\title{
LA INICIATIVA POPULAR DE REFERÉNDUM ${ }^{1}$
}

\author{
CARLOS GARRIDO LÓPEZ \\ Profesor Titular de Derecho Constitucional \\ Universidad de Zaragoza
}

SUMARIO

I. Naturaleza y funcionalidad de la iniciativa popular vinculada al referéndum en el Derecho comparado. II. Iniciativa popular y referéndums propositivos sobre normas y decisiones de transcendencia nacional. III. Iniciativa popular y referéndums de ratificación y abrogación de leyes. IV. La iniciativa popular de referéndum como factor de integración política en las democracias avanzadas. V. Los intentos de regulación de la iniciativa popular de referéndum en España: balance y perspectivas.

\section{NATURALEZA Y FUNCIONALIDAD DE LA INICIATIVA POPULAR VINCULADA AL REFERÉNDUM EN EL DERECHO COMPARADO}

En el Estado democrático, la participación del pueblo en la adopción de las decisiones colectivas discurre fundamentalmente por cauces representativos. Estos cauces no resultan, sin embargo, incompatibles con el recurso a la democracia directa. Al contrario. El principio de representación política es un pilar imprescindible en el funcionamiento de la democracia, pero ello no impide «que el poder de decisión y dirección representativo se pueda corregir y contrapesar democráticamente $[\ldots]$ mediante la decisión directa sobre ciertos asuntos por el pueblo mismo» ${ }^{2}$. A esta lógica responde la iniciativa popular para la celebración de referéndums, o iniciativa popular de referéndum, institución que, pese a las

1 Este trabajo se enmarca en el Proyecto de Investigación DER2016-75406-R sobre «Modelos de derecho comparado para una nueva regulación del referéndum y la iniciativa popular en España», financiado por el MINECO (Investigadores principales: E. Sáenz Royo y C. Garrido López).

2 E. W. BöcKENFÖRDE, «Democracia y representación: crítica sobre la discusión actual sobre la democracia», en Estudios sobre el Estado de Derecho y la democracia, Trotta, Madrid, 2000, p. 143. 
tesis sostenidas por alguna doctrina ${ }^{3}$, no cuestiona la democracia representativa ni menoscaba la posición constitucional de los parlamentos, como su reconocimiento y práctica han evidenciado en el Derecho comparado. «[...] ni la iniciativa popular, ni el referéndum — subrayó P. de Vega — pretenden suplantar los mecanismos y el ejercicio normal de los poderes constituidos. Su actuación no implica el asalto al Estado constitucional, sino que, al contrario, significa una complementación del sistema de los checks and balances, de los frenos y contrapesos que más genuinamente lo definen y caracterizan». Unos frenos que, con las debidas garantías normativas, pueden complementar la democracia parlamentaria, estimulando su representatividad y corrigiendo sus potenciales excesos.

La iniciativa popular de referéndum consiste en la atribución a un número absoluto de ciudadanos o a un porcentaje de ellos, calculado sobre los inscritos en el censo o sobre el número de sufragios emitidos en convocatorias electorales, de la facultad para instar la celebración de un referéndum sobre una cuestión política de interés general o sobre un texto normativo, remitiendo a los propios ciudadanos la decisión sobre su oportunidad política, su aprobación o su abrogación. Ideada por Condorcet con escaso éxito en su momento, esta iniciativa de referéndum atribuida a los ciudadanos forma hoy parte, sin embargo, del acervo constitucional de un buen número de democracias ${ }^{5}$. Y, a diferencia de la iniciativa atribuida a los entes subcentrales para instar la convocatoria de referéndums en algunos Estados compuestos y de la iniciativa de referéndum otorgada a las minorías parlamentarias, previstas en un reducido número de países ${ }^{6}$, su reconocimiento está bastante

3 Por todos, P. Nuss, «Référendum et iniciative populaire en France? De l'illusion en général et de l'hypocrisie en particulier», Revue du Droit Public et de la Science Politique en France et à l'étranger, núm, 5, 2000, p. 1448-1456; J. Haskell, Direct Democracy or Representive Government? Dispelling the Populist Myth, Westwiew Press, Boulder CO, 2001, pp. 11-24; D. S. Broder, Democracy Derailed: Initiative Campaigns and the Power of Money, Harcourt, New York, 2000, y G. SARTORI, ¿Qué es la democracia?, Taurus, México, 2007, pp. 157-175.

4 P. DE VEGA, La reforma constitucional y la problemática del poder constituyente, Tecnos, Madrid, 1985, p. 122.

5 Sobre la gestación y la formulación de la idea por Condorcet, A-C. MERCIER, «Le référendum d'initiative populaire: un trait méconnu du génie de Condorcet», Revue française de droit constitutionnel, n. ${ }^{\circ} 55$, 2003, pp. 483-512.

6 El reconocimiento en los Estados descentralizados de la iniciativa de referéndum a las instituciones subcentrales de autogobierno persigue lograr una mayor integración de los intereses territoriales en la voluntad general y moderar las tendencias centralizadoras de la mayoría parlamentaria nacional. En Suiza, los referéndums facultativos sobre leyes, disposiciones federales y tratados internacionales pueden convocarse a solicitud de ocho cantones (art. 141.1 Const.). En Italia, la legitimidad para instar la convocatoria se reconoce también a cinco consejos regionales en dos tipos de referéndum: en el potestativo de reforma constitucional (art. 138 Const.) y en el legislativo abrogatorio (art. 75 Cont.). El reconocimiento de la iniciativa de referéndum a una minoría parlamentaria persigue, por su parte, oponer un contrapeso a la mayoría parlamentaria y estimular la negociación entre los grupos. En Dinamarca, un tercio de los miembros del Folketing puede instar la convocatoria de un referéndum de ratificación legislativa (art. 42.1 Const.). Esta posibilidad de las minorías parlamentarias de instar referéndums sobre leyes votadas también está prevista en varios Länder alemanes. En Italia, la iniciativa para solicitar un referéndum facultativo de reforma constitucional se reconoce a una quinta parte de los miembros de cualquiera de las cámaras (art. 138 Const.). En España, la misma iniciativa se otorga a una décima parte de los diputados o senadores (art. 167.3 CE). Recientemente, Uruguay ha concedido la 
extendido en el Derecho comparado, habiéndose normalizado su práctica como instrumento ordinario de participación política directa en los ámbitos de decisión de los diversos niveles de gobierno.

En los Estados en que está instituida, la iniciativa popular de referéndum puede servir para plantear e impulsar la adopción de reformas constitucionales o decisiones políticas de trascendencia nacional. Y también como mecanismo de estímulo y de control de la acción legislativa del Parlamento. La iniciativa popular vinculada al referéndum puede contribuir a ajustar las decisiones legislativas a las demandas de los ciudadanos y operar como instrumento de veto —o de refuerzo de otros actores de veto- del predominio parlamentario a modo de eficaz contrapeso del entramado institucional ${ }^{7}$. Puede ser útil, por tanto, en una doble perspectiva: una potencialmente positiva, encaminada a dinamizar la relación representativa, enfrentar la pasividad o indiferencia de los legisladores hacia materias concretas y, en su caso, favorecer el desbloqueo entre órganos que están llamados a conformar la voluntad colectiva; otra de carácter negativo, consistente en controlar y compensar democráticamente el resultado de los procesos parlamentarios por los que habitualmente discurre la formación de la voluntad general ${ }^{8}$.

\section{INICIATIVA POPULAR Y REFERÉNDUMS PROPOSITIVOS SOBRE NORMAS Y DECISIONES DE TRANSCENDENCIA NACIONAL}

Con funcionalidad positiva, la experiencia comparada avala el referéndum propositivo de normas a iniciativa de un número de ciudadanos, a quienes se reconoce la facultad de presentar una propuesta constitucional o una propuesta legislativa para que sea votada directamente por el cuerpo electoral o para que se debata en el parlamento y, en el supuesto de ser rechazada, sea sometida a referéndum. La iniciativa popular sobre materias constitucionales posibilita a los ciudadanos proponer directamente modificaciones de la Constitución, sin intermediación de sus representantes, cuya resistencia a los cambios la ciudadanía puede así sortear. Por su parte, la iniciativa legislativa ciudadana permite plantear la regulación legislativa de cuestiones sobre las que los representantes

posibilidad de instar la convocatoria de un referéndum de reforma constitucional a dos quintos de los componentes de la Asamblea General (art. 331.B Const.); y Ecuador ha reconocido idéntica iniciativa a un tercio de los miembros de la Asamblea Nacional (art. 441 Const.).

7 Sobre las funciones de contrapeso institucional que puede desempeñar el referéndum y la iniciativa popular, M. LuCiani, «El referéndum, cuestiones teóricas y de la experiencia italiana», Revista Catalana de Dret Public, n. ${ }^{\circ}$ 37, 2008, pp. 9-12 y A. PenAdés, «Referéndums y democracia representativa», en F. GoNZÁlez, G. DAmiAni y J. Férnández-Abertos (eds.), ¿Quién manda aquí? La crisis global de la democracia representativa, Debate, Barcelona, 2016, pp. 230-231.

8 J. F. Zimmerman, The initiative: Citizen Lawmaking, 2. ${ }^{a}$ ed, State University of New York Press, Albany, 2014, pp. 186-192. 
se desentienden, o directamente rechazan, y lograr su aprobación mediante la apelación directa al cuerpo electoral.

Ambas modalidades, que permiten a los ciudadanos reaccionar ante la inactividad parlamentaria, están previstas a iniciativa de un porcentaje variable del cuerpo electoral en varios Estados de EE.UU. y, desde 1994, año en que se sumaron Turingia y Mecklemburgo-Prepomerania, y 1995, en que Berlín las reintrodujo, también las prevén la totalidad de los Länder alemanes9.

En EE.UU. ni el referéndum ni su iniciativa están regulados a nivel federal, pero veinticuatro Estados, que concentran el setenta por cierto de la población de la nación, prevén el referéndum legislativo y constitucional a iniciativa popular de un porcentaje de ciudadanos computado sobre el censo electoral o sobre el número de votos emitidos en alguna de las últimas convocatorias electorales (elecciones a gobernador del Estado, elecciones presidenciales o elecciones legislativas). Una mayoría de Estados ha optado por la iniciativa popular directa tanto para las proposiciones legislativas como para las enmiendas constitucionales ${ }^{10}$. Ello supone que las propuestas válidamente suscritas deben someterse necesariamente a votación popular. En otros Estados, en cambio, las iniciativas normativas de los ciudadanos son remitidas al parlamento para su deliberación y votación. Y si en un plazo determinado — que fluctúa entre los 40 días en Michigan y Nevada hasta el fin del mandato parlamentario en Maine- no son asumidas por los representantes políticos, deben someterse a referéndum. En Utah y Washington los promotores de las iniciativas legislativas pueden escoger entre ambas modalidades de iniciativa, la directa o la indirecta. Michigan, Nevada y Ohio prevén la iniciativa popular directa para las enmiendas constitucionales y la iniciativa indirecta para las proposiciones de ley. Illinois y Florida reconocen exclusivamente el procedimiento de iniciativa directa de enmiendas constitucionales. E Idaho sólo prevé la iniciativa popular directa de proposiciones legislativas. En Massachussets, donde la iniciativa popular existente es indirecta tanto para enmiendas constitucionales como para proposiciones legislativas, el parlamento puede presentar un proyecto normativo alternativo al popular, que se somete a votación junto con la propuesta ciudadana. La formulación de esta alternativa para someterla a votación junto con la propuesta ciudadana también está prevista en los Estados que sólo admiten la iniciativa legislativa indirecta ${ }^{11}$. $Y$ en California, donde la iniciativa es

9 La posibilidad de convocar a iniciativa popular referéndums de reforma constitucional y sobre proposiciones legislativas fue constitucionalizada en los Länder de Baviera, Berlín, Bremen, Hesse, Renania del Norte-Westfalia y Renania Palatinado entre 1945 y 1950. En la década de los setenta, tras la reforma de sus constituciones, reconocieron la iniciativa popular de referéndum Baden-Gürttemberg y Sarre. Y entre 1990 y 1995 lo hicieron el resto de Länder, incluido la ciudad-Estado de Berlín, que recuperó en 1995 los referéndums a iniciativa popular después de que la reforma constitucional de 1974 los hubiera eliminado de la Constitución de 1950.

10 Es el caso de los Estados de Arizona, Arkansas, California, Colorado, Dakota del Norte, Dakota del Sur, Missouri, Montana, Nebraska, Oklahoma y Oregón.

11 Sobre las singularidades de las iniciativas directas e indirectas en los Estados que las han regulado, G. Alan Tarr, Understanding State Constitutions, Princeton University Press, Princeton, 1998, pp. 118-126, 
necesariamente directa, desde septiembre de 2014 se permite que los promotores puedan retirar su propuesta en caso de obtener una respuesta satisfactoria de las instituciones representativas, lo que estimula la receptividad de la clase política, así como la negociación y el pacto previos a la convocatoria del referéndum solicitado $^{12}$. Una muestra muy significativa de esta dinámica se produjo en 2016, cuando el sindicato de salud de ese Estado anunció que ya tenía las firmas suficientes para que se votara en referéndum su propuesta de aumento del salario mínimo a 15 dólares la hora. En una semana, el gobernador y el legislativo de California negociaron con los promotores y pactaron una ley un poco más matizada (varios años de plazo, aumentos progresivos hasta llegar a 15 dólares y la posibilidad de frenar la subida salarial si la situación económica es adversa), lo que evitó, al ser atendida durante la negociación, que la iniciativa fuera votada en referendum ${ }^{13}$.

En Alemania, la Grundgesetz no prevé la iniciativa popular de referéndum a nivel federal. Las constituciones de los Länder han regulado, en cambio, esta iniciativa generosamente, y a su amparo se han celebrado en los últimos años más de 220 referendos estatales sobre cuestiones constitucionales y legislativas de su competencia. La iniciativa popular para someter a referéndum reformas constitucionales y proposiciones legislativas se reconoce a un número absoluto de votantes o a un porcentaje del cuerpo electoral de cada Land, que oscila entre el cuatro por ciento exigido en Brandemburgo y el veinte por ciento en Hesse y Sarre para referéndums propositivos de leyes, y entre el cuatro o cinco por ciento de Brandemburgo, Hamburgo y Schleswig-Holstein y el veinte por ciento del electorado en Berlín, Bremen, Hesse y Sarre para referéndums constitucionales. En la totalidad de los Länder, la iniciativa popular debe presentarse debidamente articulada al Landtag, que puede aprobarla sin enmiendas o respetando su contenido

y T. Donovan, «Referendums and Initiatives in North America», M. Qvortrup (ed.), Referendums Around the World, Palgrave Macmillan, New York, 2014, pp. 122-153. También, G. Alan TARr, «Direct Democracy in United States», ponencia defendida en el Seminario de investigación sobre el referéndum y su iniciativa en perspectiva comparada, 25 de octubre de 2017, Palacio de la Aljafería, Zaragoza. En la doctrina española, V. Cuesta LóPez, Participación directa e iniciativa legislativa del ciudadano en democracia constitucional, Aranzadi, Pamplona, 2008, pp. 279-280.

12 En septiembre de 2014, una coalición en la que estaba el Comité de Ideas a Largo Plazo para California del Instituto «Berggruen» de Santa Mónica propuso y consiguió que se aprobara un retoque del sistema, de forma que los autores de una iniciativa puedan retirarla en caso de que encuentren una respuesta satisfactoria de las instituciones. La Ley SB 1253, que acometió esta reforma, ha ampliado el período de recogida de firmas e introducido un período de consulta pública al inicio del proceso durante el cual los promotores de la iniciativa pueden modificarla a la vista de las alegaciones formuladas por las instituciones, los grupos de interés o los ciudadanos. En otros Estados (Alaska, Idaho, Montana, Nebraska, Utah y Wyoming) se reconoce el derecho de los signatarios de las propuestas a retirar su apoyo, pero sólo antes de que la administración electoral realice la verificación de firmas.

13 El gobernador de California, J. Brown Jr, firmó el 4 de abril de 2016 la legislación histórica que convirtirá a California en el primer Estado de EE.UU. que incrementará el salario mínimo a 15 dólares la hora para el año 2022 en empresas grandes y para 2023 en empresas pequeñas. La legislación aumenta con el tiempo el salario mínimo y, al mismo tiempo, prevé válvulas de seguridad para detener los aumentos de salarios si surgen condiciones económicas o presupuestarias adversas. 
esencial, introducir enmiendas a la proposición u optar por rechazarla. En el caso de resultar aceptada, la iniciativa popular articulada queda aprobada y el referéndum no se celebra. De introducirse enmiendas o resultar rechazada por el parlamento, la iniciativa popular debe, en cambio, someterse a referéndum del cuerpo electoral. Un referéndum en el que, en los Länder de Baden-Württemberg, Baja Sajonia, Baviera, Berlín, Hamburgo, Mecklemburgo-Prepomerania, Renania-Palatinado, Sajonia, Sajonia-Anhalt, Sarre, Schleswig-Holstein y Turingia, podrá además someterse a consulta, junto con la iniciativa popular no asumida por el Landtag, la propuesta alternativa o contraproyecto que el propio Landtag puede elaborar, debiendo los votantes optar por uno de los dos textos articulados ${ }^{14}$.

En Suiza, sólo está prevista con perfil propositivo la iniciativa popular de revisión constitucional. El artículo 138 de la Constitución otorga a 100.000 electores la facultad de proponer su revisión total, iniciativa que directamente se somete a referéndum popular. El artículo 139 de la Constitución faculta al mismo número de electores para proponer revisiones constitucionales parciales, que pueden presentarse ante la Asamblea federal integralmente redactadas o en forma de proposiciones generales, debiendo respetar el principio de unidad de forma y unidad de materia y con el único límite de que no contravengan las reglas imperativas del derecho internacional.

En el caso de las proposiciones generales, la Asamblea federal ha de pronunciarse mostrando su aceptación o rechazo a la iniciativa popular. Si la Asamblea federal comparte las iniciativas populares concebidas en términos generales, debe desarrollarlas y articularlas antes de la convocatoria del referéndum, sometiéndose entonces el texto resultante al escrutinio popular y de los cantones. Si, por el contrario, la Asamblea Federal muestra su rechazo, lo que se somete a referéndum son las iniciativas genéricas de revisión y, de ser aprobadas por el pueblo, la Asamblea federal queda obligada a desarrollarlas a posteriori (art. 139.4 Const.), tras lo cual el texto resultante debe someterse al voto del pueblo y de los cantones en un segundo referéndum.

En el supuesto de las iniciativas populares íntegramente redactadas, la Asamblea federal debe hacer pública su posición y, simultáneamente, puede elaborar un contraproyecto sobre la misma materia, en cuyo caso los ciudadanos tienen derecho a pronunciarse simultáneamente sobre la iniciativa popular y el contraproyecto (art. $139 b$ Const.). En la votación, según prevé el artículo 76 de la Ley de Derechos Políticos reformado en 2000, los electores deben responder, en primer lugar, si prefieren, o no, el texto de la iniciativa popular a la regulación constitucional vigente; en segundo lugar, si prefieren, o no, el contraproyecto parlamentario a la regulación

14 A. WeBER, «Direckte Demokratie im Landesverfassungsrecht», en Die Öffentliches Verwaltung (DöV), 1985, pp. 178-184, y el completo informe sobre iniciativas populares y referéndums de F. REHMET y T. WeBer, Volksbegehrensbericht 2017. Direkte Demokratie in den deutschen Bundesländern 1946 bis 2016, Mehr Demokratie e.V., Berlín, 2017, disponible en: https://www.mehr-demokratie.de/fileadmin/pdf/volksbegehrensbericht_2017.pdf. 
constitucional vigente, y en tercero, cuál de los dos textos de reforma parcial debería entrar en vigor en el caso de que el pueblo y los cantones los hayan preferido a la regulación vigente, a fin de resolver con esta cuestión subsidiaria el problema que podría derivarse de la aceptación de ambos textos en las respuestas anteriores. Se concilia así la libertad de voto y la igualdad de oportunidades entre la iniciativa popular, el contraproyecto y el status qu1 ${ }^{15}$.

La ausencia de límites materiales expresos más allá de la prohibición de vulnerar el ius cogens internacional, ha permitido que la iniciativa popular para revisiones parciales de la Constitución haya servido en Suiza para canalizar la regulación de propuestas normativas que poco tienen que ver con el contenido tradicional de las normas constitucionales y que deberían haberse formalizado en leyes o, incluso, en reglamentos federales. Ello, unido a la inexistencia de una vía para instar popularmente la convocatoria de referéndums sobre proposiciones legislativas, ha llevado a un uso generalizado de esta modalidad como un trasunto del referéndum propositivo de leyes, habiéndose celebrado más de 200 referéndums de revisión parcial de la Constitución desde 1874, año en el cual la segunda Constitución federal entró en vigor ${ }^{16}$. El ejercicio de la iniciativa popular de reforma parcial ha convertido de este modo el texto constitucional suizo «en una realidad cambiante, alejada de una fijación definitiva y cerrada del orden de convivencia en un momento constituyente, de modo que el debate constitucional se proyecta en el tiempo. [...] En este sentido, el alejamiento de la praxis constitucional en relación a la idea de poder constituyente es manifiesta» ${ }^{17}$. A fin de reconducir esta dinámica y canalizar las iniciativas hacia reformas legislativas, en 2003 se introdujo en el artículo 139a de la Constitución federal la llamada «iniciativa popular general», mediante la que un mínimo de cien mil electores podían proponer a la Asamblea en términos generales la adopción, modificación o abrogación de disposiciones constitucionales o legislativas para que ésta, de aceptar, las articulara posteriormente formalizándolas a través de la fuente más idónea, que en la mayoría de los casos sería de rango legal. El referéndum debía celebrarse en todo caso, tanto si la Asamblea rechazaba la iniciativa general como si la asumía y articulaba, votándose en la segunda hipótesis las modificaciones redactadas

15 Sobre el funcionamiento de la iniciativa popular de revisión de la Constitución en Suiza, U. SERDÜLT, «Referendums in Switzerland», M. Qvortrup (ed.), Referendums Around the World, cit., New York, 2014, pp. 43-64, y E. GRISEL, Iniciative et referendum populaires. Traité de democratie semi-directe en droit suisse, $3^{\text {e }}$ éd., Stämpfli Verlag, Berne, 2004, pp. 181-190, 203-219 y 259-269.

16 Los referendos suizos, su objeto y sus resultados pueden verse cronológicamente en la web de la Cancelleria Federale: https://www.bk.admin.ch/ch/f/pore/va/vab_2_2_4_1_gesamt.html.

17 J. Jaría I Manzano, «La Constitución es un proceso. Poder constituyente y reforma constitucional en Suiza», en J. M. ${ }^{a}$ CASTEllà Andreu (ed.), Parlamento, ciudadanos y entes territoriales ante la reforma constitucional. ¿Quién y cómo participa?, Tirant lo Blanch, Valencia, 2018, p. 93. Como J. L. ReQuejo Pagés señaló, dado el protagonismo de la iniciativa popular de referendum, la Constitución suiza es más «la descripción del Derecho constitucional vigente en cada momento histórico por la sucesiva acumulación de decisiones constituyentes del cuerpo electoral, que la prescripción de una voluntad normativa concreta con vocación de perpetuidad». Cfr. «La reforma de las constituciones cantonales suizas», REP, n. ${ }^{\circ} 151,2011$, p. 366. 
por la Asamblea en desarrollo de la iniciativa y el contraproyecto alternativo que hubiera podido elaborar. Esta modalidad de iniciativa popular, que permitía la proposición de leyes, no tuvo, sin embargo, el desarrollo necesario para ponerla en práctica y fue abrogada en referéndum el 27 de septiembre de $2009^{18}$.

En Latinoamérica, Uruguay, Colombia, Costa Rica y Ecuador también han reconocido la iniciativa popular de referéndum propositivo de reforma constitucional. En Colombia (art. 374 Const.) y Costa Rica (art. 105 Const.) el referéndum de reforma puede solicitarlo un cinco por ciento de los electores. En Ecuador, la iniciativa para instarlo se atribuye al ocho por ciento de las personas inscritas en el Registro Electoral (art. 441.1 Const.), y en Uruguay, al diez por ciento del cuerpo electoral (art. 331.A Const.). Colombia también prevé la iniciativa popular de referéndum para la aprobación de un proyecto de ley, de ordenanza, de acuerdo o de resolución local de iniciativa popular que sea rechazado por la corporación respectiva o no haya sido debatido en plazo en el parlamento, atribuyéndola a un diez por ciento del censo electoral nacional, departamental o municipal (art. 32 de la Ley 134 de 1994) ${ }^{19}$.

A diferencia de los supuestos anteriores, Francia no regula la iniciativa popular de referéndum propositivo de revisión constitucional. Tras la reforma constitucional de 2008, sí prevé, en cambio, una suerte de iniciativa popular, concurrente con la iniciativa de una minoría parlamentaria, que puede dar lugar a la celebración de referéndums sobre proposiciones legislativas que versen sobre la organización de los poderes públicos, sobre reformas relativas a la política económica, social y medioambiental de la Nación y a los servicios públicos que concurren en ella, o que propongan la ratificación de un tratado que, sin ser contrario a la Constitución, pueda tener incidencias en el funcionamiento de las instituciones (art. 11 Const.). La iniciativa legislativa se atribuye a una quinta parte de los miembros de la Asamblea Nacional, pero debe ser completada o perfeccionada por el concurso de, al menos, una décima parte del cuerpo electoral y superar el control de admisibilidad y el posterior control de las firmas por parte del Consejo Constitucional. $\mathrm{Si}$, cumplidos los trámites, la proposición legislativa no es examinada por ambas Cámaras en el plazo de seis meses desde la publicación de la decisión del Consejo que constata la existencia del apoyo popular requerido (art. 9 de la Ley Orgánica n. ${ }^{\circ}$ 2013-1114, de 6 de diciembre), el Presidente de la República debe someterla a referéndum ${ }^{20}$. Pese a ser presentada como un avance democratizador que rompía

18 La iniciativa «genérica» o «de tipo único» está regulada, y es usada, en cambio, en varios cantones, y, de prosperar en referéndum, queda en manos del parlamento cantonal la función de determinar el rango normativo, constitucional o legislativo, de su desarrollo. E. Grisel, Iniciative et referendum populaires. Traité de democratie semi-directe en droit suisse, cit., p. 212.

19 F. Soto BARrientos, «El referéndum en Latinoamérica: un análisis desde el derecho comparado», Boletín Mexicano de Derecho Comparado, año XLVI, n. ${ }^{\circ} 136,2013$, pp. 317-346.

20 Sobre la introducción de esta modalidad de iniciativa de referéndum, F. HAMON, «La nouvelle procedure de l'article 11: un vrai faux référendum d'initiative populaire», Petites Affiches, n. ${ }^{\circ} 254,2008$, págs. 16-21 y S. Diemert, «Le référendum legislatif d'initiative minoritaire dans l'article 11, révisé, de la 
el monopolio referendario del Presidente de la República, el elevado porcentaje de ciudadanos exigido y el necesario concurso parlamentario han impedido, hasta la fecha, que esta vía participativa haya sido usada. No es extraño, por ello, que, debido a las limitaciones de la iniciativa compartida, el grupo de trabajo sobre el futuro de las instituciones, constituido en la Asamblea Nacional en 2015, haya apostado por «instaurer un véritable référendum d'initiative populaire», porque «la hiérarchie entre parlementaires et citoyens, qui remet, dans les faits, l'initiative référendaire entre les mains des premiers, fait du référendum prévu au troisième alinéa de l'article 11 un référendum à l'initiative d'une minorité de parlementaires, plutôt qu'un instrument de démocratie directe» ${ }^{21}$.

En Italia, el referéndum propositivo de leyes a iniciativa popular se ha reconocido en los estatutos de segunda generación de las regiones de Calabria, Campania, Cerdeña, Friuli-Venecia Julia, Lacio y Valle de Aosta. La facultad de impulsar la iniciativa legislativa corresponde a un cinco por ciento y un diez por ciento del electorado en Valle de Aosta y Calabria, respectivamente, y a 15.000 electores en Cerdeña, 30.000 electores en Friuli-Venecia Julia y 50.000 electores en Campania y Lacio. En las seis regiones, las iniciativas legislativas deben ser remitidas al Consejo para su discusión. De no ser examinadas en un plazo determinado por el Consejo regional (casos de Calabria, Cerdeña y Lacio), o de resultar rechazadas (casos de Campania, Friuli-Venecia Julia y Valle de Aosta), la convocatoria del referéndum resulta preceptiva ${ }^{22}$. En el ámbito nacional, la Constitución italiana regula la iniciativa legislativa popular, pero no la vincula al referéndum y no prevé, como las citadas regiones, el referéndum propositivo de leyes a resultas de una iniciativa popular $^{23}$. En la práctica sin embargo, el referéndum legislativo abrogatorio a soli-

Constitution», Revue française de droit constitutionnel, n. ${ }^{\circ}$ 77, 2009, pp. 55-97. En la doctrina española, P. Requejo RodríGuez, «Ciudadanos menores de edad», REDC, n. ${ }^{\circ}$ 99, 2013, 204-215.

21 Cfr. M. C. Bartolone y M. Winock (dirs.), Refaire la démocratie, Rapport n. ${ }^{\circ} 3100$, Assemblée Nationale, Paris, 2015, pp. 70-73, en http://www2.assemblee-nationale.fr/static/14/institutions/Rapport_ groupe_travail_avenir_institutions_T1.pdf).

22 Un análisis de la iniciativa propositiva de leyes vinculada al referéndum en las regiones italianas de régimen especial (Friuli-Venecia Julia, Cerdeña y Valle de Aosta) y régimen ordinario (Campania, Calabria y Lacio), en N. RODEAN, «La democracia directa en Italia: iniciativa ciudadana y referéndum en la fallida reforma constitucional y en los estatutos de segunda generación», E. SÁENZ Royo y C. GARRIDo López (coords.), La funcionalidad del referéndum en la democracia representativa, Tirant lo Blanch, Valencia, 2017, pp. 395-403.

23 Recientemente, los partidos que sustentan el actual Gobierno italiano, la Liga Norte y el Movimiento 5 Estrellas, han presentado dos propuestas de reforma del artículo 71 de la Constitución que reconocerían la iniciativa legislativa popular reforzada o vinculada al referéndum de naturaleza propositiva. Superado el control de admisibilidad de la iniciativa legislativa atribuido a la Corte Constitucional, que debería respetar los derechos fundamentales garantizados por la Constitución y las obligaciones internacionales, el referéndum sobre la iniciativa legislativa deberá celebrarse si las Cámaras modifican la propuesta ciudadana o no la aprueban en el plazo de dieciocho meses desde su presentación. En el primer caso, el texto aprobado por las Cámaras se sometería a consulta junto con el texto de la iniciativa legislativa popular, resultando aprobado el que obtuviera el mayor número de votos. Vid. Proposta di legge Costituzionale C 726, de 13 de julio de 2018 y Proposta di legge Constituzionale C 1173, disponibles, respectivamente, en http://documenti.camera.it/leg18/pdl/pdf/ leg.18.pdl.camera.726.18PDL0025860.pdf y http://documenti.camera.it/leg18/pdl/pdf/leg.18.pdl.camera.1173.18PDL0028960.pdf. 
citud de 500.000 ciudadanos previsto en el artículo 75 de la Constitución suele tener un alcance materialmente propositivo, porque sus promotores, seleccionando las partes de las leyes que se pretenden derogar sólo parcialmente, pueden provocar la innovación del ordenamiento jurídico generando realmente nuevas normas al convertir al cuerpo electoral en legislador alternativo. Olivetti explica con claridad esta mutación constitucional: dado que el referéndum legislativo previsto constitucionalmente «sólo puede ser derogatorio (no puede, por tanto, someterse a votación popular la propuesta de un nuevo texto legislativo) y, por otro lado, no puede generar, en algunas materias, un vacío legislativo, será necesario redactar una pregunta que, derogando sólo algunas partes del texto, deje en vigor un texto residual capaz de expresar una normativa dotada de sentido y aplicable. [...] Pero de ese modo el referéndum pierde su carácter puramente derogatorio para convertirse en un procedimiento que permite el nacimiento de una nueva ley, distinta de la precedente, sin que sea necesario recurrir a la votación de un texto legislativo formalmente nuevo» ${ }^{24}$.

Con funcionalidad también positiva, otros Estados prevén la iniciativa popular de referéndum sobre cuestiones de trascendencia nacional, expresión genérica bajo la que los ciudadanos pueden ser convocados para decidir sobre reformas constitucionales, delegación de poderes a entidades supranacionales o cuestiones de alcance cuya irreversibilidad aconseja su adopción por el pueblo mismo ${ }^{25}$. En Colombia, la iniciativa popular para convocar consultas sobre asuntos de trascendencia nacional se otorga a un cinco por ciento del censo electoral, debiendo pronunciarse el Senado sobre la oportunidad de la convocatoria en el plazo de un mes [arts. 9 y 20.d) de la Ley 1757 de 6 de julio de 2015]. En México se concede al dos por ciento de los electores censados (art. 35.VIII Const.). En Nueva Zelanda, la Citizens Initiated Referenda Act 1993 reconoce la iniciativa de referéndum sobre cuestiones nacionales a un diez por ciento de los inscritos en el censo electoral. En Hungría, se convoca automáticamente referéndum sobre «cuestiones políticas fundamentales» si la solicitud va firmada por más de 200.000 ciudadanos; y con el concurso de la mayoría de la Asamblea si el referéndum ha sido solicitado por menos de 200.000 pero por más de 100.000 electores (art. 8.1 «El Estado» de la Ley Fundamental). Países

24 M. OlivetTi, «Los referendos en serio: la experiencia italiana», RJUAM, n. ${ }^{\circ} 15,2007$, p. 159. Analizan también esta mutación constitucional del alcance normativo del referéndum abrogatorio, G. RoLLA, «Las dinámicas entre el referéndum, las instituciones de democracia representativa y los partidos políticos. Consideraciones a la luz de la experiencia italiana», en P. Biglino CAMPOS (coord. ${ }^{a}$.), Partidos políticos y mediaciones de la democracia directa, CEPC, Madrid, 2017, pp. 229-231, y A. SÁIz ARNÁIz, «El referéndum derogatorio en el ordenamiento italiano: entre las (incompletas) previsiones normativas y la (creativa) jurisprudencia constitucional», REDC, n. ${ }^{\circ} 36,1992$, pp. 197-198.

25 Se trataría en estos casos, como ha señalado H. P. Schneider, de descargar de responsabilidad al Parlamento en aquellas decisiones críticas, denominadas «decisiones de nuevo tipo» por el autor, cuyo alcance e irreversibilidad, o sus repercusiones internacionales, comprometen a las generaciones futuras. Cfr. «Soberano sin poder. Representación y participación del pueblo como problema de legitimación de la soberanía democrática», Democracia y Constitución, CEC, Madrid, 1991, pp. 260-261. 
Bajos ha reconocido la iniciativa de referéndum sobre cualquier asunto de interés nacional a 300.000 ciudadanos (Wet raadgevend referendum op 1 julio 2015) y Polonia otorga la iniciativa a 500.000 ciudadanos (artículo 125 Const. y Ley de referéndum de 14 de marzo de 2003). Rusia confiere la iniciativa para referéndums sobre asuntos de interés nacional a 2 millones de electores que han de estar distribuidos entre la mitad de las unidades territoriales de la Federación. Y Lituania, en fin, la atribuye a 300.000 electores (Ley IX-929/2002, de 4 de junio), haciendo así posible la intervención del cuerpo electoral, a instancias de los propios electores, frente a la inercia o pasividad de las instituciones representativas.

\section{INICIATIVA POPULAR Y REFERÉNDUMS DE RATIFICACIÓN Y ABROGACIÓN DE LEYES}

También con funcionalidad normativa, en este caso negativa, el Derecho comparado ha reconocido la iniciativa popular de referéndum para ratificar leyes recientemente votadas y/o para abrogar leyes en vigor, y su función correctora y de contrapeso de la actividad parlamentaria resulta de primer orden, en la medida en que posibilita en último término el ejercicio de una suerte de «facultad de veto» del cuerpo electoral sobre la actividad legislativa.

La primera modalidad, consistente en instar la ratificación o suspensión legislativa de textos votados por el parlamento, fue constitucionalizada en Suiza en 1874 bajo la denominación de referéndum facultativo. Su convocatoria procede si lo solicitan 50.000 electores u ocho cantones en un plazo de 100 días a contar desde la publicación oficial de la ley o la disposición federal discutida o de los tratados internacionales que tengan una duración indeterminada y no sean denunciables, prevean la adhesión a un organismo internacional o contengan disposiciones que fijen las reglas de derecho o cuya ejecución exija la adopción de leyes federales (art. 141 Const.). Esta modalidad de referéndum facultativo a instancia popular no sólo está prevista a nivel federal, sino también en las constituciones de los cantones, habiéndose celebrado en ambos ámbitos territoriales cientos de ellos ${ }^{26}$. En Letonia, el referéndum de ratificación legislativa puede celebrarse a solicitud de un diez por ciento de los inscritos en el censo si la ley ha sido suspendida por el Presidente de la República (art. 1.3 Law on National Referendums Initiation of Laws and European Citizens Initiative, 1994), y en Eslovenia, si así lo solicitan 40.000 ciudadanos (art. 90 Const.).

En los Estados de EE.UU. que reconocen a los ciudadanos la posibilidad de convocar referéndums sobre leyes aprobadas por las legislaturas, la iniciativa se

26 H. Kriesi y A. Trechsel, «Switzerland: the referendum and initiative as centerpiece of the political system», M. Gallagher y P. V. Uleri (eds.). The Referendum Experience in Europe, Macmillan Press LTD, London, 1996, pp. 185-208. 
otorga a una fracción de electores calculada sobre el censo o sobre el porcentaje de participación habida en las elecciones precedentes. La mayoría de las leyes estatales, salvo que medie declaración de emergencia legislativa, no entran en vigor inmediatamente después de su aprobación por la legislatura estatal, sino que se suspenden por un período, generalmente de 90 días, durante el cual los votantes tienen la oportunidad de solicitar un referéndum sobre la ley. Y si los promotores de la iniciativa recopilan las firmas suficientes para convocar un referéndum, la entrada en vigor de la ley se suspende hasta que los votantes emitan su opinión en las urnas ${ }^{27}$.

La segunda modalidad, en la que una ley en vigor puede ser abrogada total o parcialmente mediante referéndum instado popularmente, también está extendida en el Derecho comparado. En Latinoamérica, la iniciativa popular de referéndum abrogatorio de leyes se reconoce a un porcentaje sobre censo: en Uruguay, el referéndum se convoca a petición de un veinticinco por ciento del cuerpo electoral, formulada dentro del primer año a partir de la promulgación de la ley (art. 79 Const.); en Venezuela, a iniciativa de un diez por ciento de los electores (art. 74 Const.); en Colombia, a iniciativa de un diez por ciento del censo (art. 170 Const.), y en Ecuador y Costa Rica, a iniciativa de un cinco por ciento de personas inscritas en el registro electoral en ambos casos (arts. 104 y 105 de sus respectivas Constituciones).

En Alemania, las constituciones de los Länder de Berlín (art. 62), Bremen (art. 70), Mecklemburgo-Prepomerania (art. 60), Baja Sajonia (art. 48), Sarre (art. 72) y Sajonia-Anhalt (art. 81) reconocen la iniciativa popular de referéndum para la modificación o derogación de leyes a un número absoluto de votantes o un porcentaje del cuerpo electoral, según los casos. En Italia, el referéndum abrogatorio, total o parcial, de leyes o actos con fuerza de ley puede celebrarse a iniciativa de 500.000 electores o de cinco consejos regionales, siempre que no afecte a leyes tributarias y presupuestarias, de amnistía e indulto, ni de autorización para ratificar tratados internacionales (art. 75.2 Const. ${ }^{28}$. La iniciativa popular de referéndum abrogatorio de leyes también está prevista en los estatutos de las regiones italianas. En el ámbito regional el uso de esta iniciativa ha sido hasta la fecha marginal, pero la situación ha sido distinta a escala nacional, donde, desde 1974, se han celebrado 67 referéndums abrogatorios a instancia popular sobre

27 El Estado de Nebraska constituye a este respecto una excepción. Si los opositores a la ley no alcanzan el diez por ciento de firmas de los votantes registrados, la ley permanece en vigor hasta que se celebre el referéndum. Sólo si se supera ese porcentaje de firmas, la ley se suspende.

28 En el ejercicio de su facultad de control de las materias excluidas de referéndum, la Corte Constituzionale ha ampliado interpretativamente las materias citadas en el artículo 75.2 de la Constitución excluyendo también de referéndum las leyes de reforma constitucional, otras leyes constitucionales y los actos legislativos reforzados que no puedan ser derogados por leyes ordinarias, las «disposiciones legislativas ordinarias con contenidos constitucionalmente vinculados y las disposiciones que producen efectos vinculados a las materias que el artículo 75.2 de la Constitución enumera» (Sentencia n. ${ }^{\circ}$ 27/1987). Sobre la ampliación por vía jurisprudencial de los límites materiales de la iniciativa popular de referéndum, A. PERTICI, Il gindice delle leggi e il giudizio di ammissibilità del referéndum abrogativo, Giappichelli Editore, Turín, 2010, pp. 134-140. 
temas tan dispares y sensibles como el divorcio, la financiación pública de partidos, la despenalización del aborto, la investigación con embriones y fecundación asistida, el sistema electoral, la edad de jubilación, la energía nuclear, las privatizaciones del agua y los impedimentos procesales a favor de los miembros del Gobierno. De 1997 a 2009 ninguno de los referéndums abrogatorios celebrados superó el $50 \%$ de participación popular exigido para conferir validez al resultado $^{29}$, pero ello no ha impedido que esta modalidad participativa siga siendo uno de los rasgos característicos del sistema político italiano.

Como Rolla ha subrayado, la iniciativa popular de referéndum contribuye en Italia a «reforzar el vínculo representativo que une al pueblo con el Parlamento ${ }^{30}$. La amenaza de activar una iniciativa abrogatoria frente a decisiones legislativas adoptadas por mayorías precarias estimula claramente la negociación en sede parlamentaria; de activarse, sirve para canalizar institucionalmente el descontento popular; formalizada la iniciativa, los parlamentarios tienen la posibilidad de decidir derogar los preceptos cuestionados antes de la celebración del referéndum; de no hacerlo y celebrarse la consulta, los votantes pueden confirmar la decisión legislativa — lo que ocurre en la mayoría de los casos_ o, superado el quórum exigido para que la voluntad popular expresada sea suficientemente significativa para imponerse ${ }^{31}$, pueden por el contrario corregir la actividad legislativa del Parlamento, optando por la abrogación de la ley. Nada de ello, en puridad,

29 En Italia, el referéndum legislativo abrogatorio carece de validez si el número de votantes no supera el $50 \%$ de los inscritos en el censo electoral (art. 75 Cont.). Dicho quórum, que no se exige en cambio para el referéndum de reforma constitucional (art. 138 Cont.), no se alcanzó en los referéndums abrogatorios celebrados de 1977 a 1996, pero a partir de ese momento, y durante más de una década, cundió la táctica de los opositores de los diferentes referéndums de invitar a los electores a no acudir a las urnas, superándose tan sólo el porcentaje de validez requerido en los referéndums abrogatorios de 2011. Los referéndums abrogatorios italianos y su respectiva participación, en http://elezionistorico.interno.it/index.php?tpel=F.

30 G. Rolla, «Las dinámicas entre el referéndum, las instituciones de democracia representativa y los partidos políticos. Consideraciones a la luz de la experiencia italiana», cit., p. 216.

31 La exigencia de quórum para conferir validez a los resultados de los referéndums es una garantía relativamente extendida en el Derecho comparado que pretende evitar la adopción de decisiones cuando la participación popular sea escasa en relación con el censo o con la participación habida en las elecciones y la representatividad institucional resultante. En Italia, el referéndum abrogatorio de ámbito nacional debe superar el $50 \%$ de participación computado sobre el censo electoral. En los referéndums abrogatorios de ámbito regional también se exige un quórum superior al 50\%, con la excepción de la Toscana, cuyo estatuto regional condiciona la validez del referéndum a la participación de una mayoría de votantes computada sobre la participación habida en las últimas elecciones regionales. Los Länder alemanes, con la excepción de Baviera, Hesse y Sajonia, exigen para conferir validez a los referéndums legislativos de iniciativa popular entre un $15 \%$ (caso de Renania del Norte-Westfalia) a un $50 \%$ de participación (Sarre) calculado sobre el censo; y en los referéndums de reforma constitucional (regulados en todos los Länder menos en Hesse y Sarre) el quórum exigido oscila entre el 25\% (Baviera), el 40\% (Turingia) y el 50\% de participación (el resto de Länder). En Países Bajos, la ley exige para la validez del referéndum que la participación supere el $30 \%$ del censo electoral. En Hungría, el referéndum sólo es válido si han participado más de la mitad de los inscritos en el censo (art. 8.4 «El Estado» de la Ley Fundamental). En contra de esta garantía se ha pronunciado, sin embargo, el Code of Good Practice on Referendums (punto 7), elaborado por el Consejo de Europa, al considerar que la exigencia de quórum alienta estratégicamente a los opositores de la propuesta a la abstención (Disponible en http://www. venice.coe.int/webforms/documents/default.aspx?pdffile=CDL-AD(2007)008rev-spa.). 
contradice la lógica de la representación democrática, porque, como subrayó Carré de Malberg, no cabe defender la idea de que la representación hace presente la voluntad popular y no reconocer al tiempo «el derecho de los ciudadanos a manifestar un sentimiento distinto a aquél que, sobre una cuestión determinada, ha sido manifestado en su nombre por los representantes $»^{32}$.

\section{LA INICIATIVA POPULAR DE REFERÉNDUM COMO FACTOR DE INTEGRACIÓN POLÍTICA EN LAS DEMOCRACIAS AVANZADAS}

En todas estas modalidades de referéndum, la posibilidad reconocida a un número significativo o un porcentaje de ciudadanos de trasladar la decisión al cuerpo electoral influye decisivamente en el desarrollo y la capacidad de integración política de las instituciones representativas ${ }^{33}$. Estando legitimadas para solicitar la celebración de consultas populares, las minorías políticas y las organizaciones de la sociedad civil pueden presionar a los partidos mayoritarios anunciando que, si sus demandas o preocupaciones nos son escuchadas por el legislador, están dispuestas a promover la convocatoria de un referéndum propositivo, suspensivo o abrogatorio. Ello favorece la negociación e integración de los intereses en sede parlamentaria. Ante la incertidumbre del resultado en un referéndum, la mayoría parlamentaria tiende a ser receptiva a fin de evitar su convocatoria o, en el supuesto de producirse ésta, esa mayoría suele mostrarse integradora, como ocurre en Suiza con las contrapropuestas parlamentarias que la Asamblea puede formular, que se someten a consulta simultáneamente con las proposiciones ciudadanas y suelen ser las preferidas de los votantes por su vocación y contenido conciliador ${ }^{34}$. Y lo mismo ocurre en los numerosos Länder alemanes y en los Estados de EE.UU. que prevén la formulación de propuestas alternativas por los parlamentos estatales. Por las razones anteriores, la iniciativa popular de referéndum, en cualquiera de sus modalidades, representa un estímulo para la búsqueda continuada del compromiso entre las fuerzas políticas y entre éstas y las organizaciones de la sociedad civil.

Cuando los gobiernos o las mayorías parlamentarias controlan el referéndum tienden a usarlo para reforzar su posición de poder y a fin de doblegar la resistencia y los contrapesos de otras instituciones democráticas. A mayor número de

32 R. Carré De Malberg, «Consideraciones teóricas a propósito de la relación del referéndum con el parlamentarismo», RDCE, n. ${ }^{\circ} 21,2014$, p. 298.

33 E. R. Gerber, «Legislative Response to the Threat of Popular Initiatives», American Journal of Political Science, vol. 40, n. ${ }^{\circ} 1,1996$, pp. 99-102.

34 «The referendum has given rise to the so-called 'politics of condordance', implying that all interest groups that are capable of imposing a veto through the rejective initiative are included in the legislative process». Cfr. H. Kriesi y A. Trechsel, «Switzerland: the referendum and initiative as centerpiece of the political system», cit., p. 202. 
sujetos proponentes, en cambio, la tentación de utilización plebiscitaria del referéndum se reduce y su funcionalidad democrática aumenta, porque suma un poder corrector al sistema. Los referendos impulsados «desde abajo», a través de las iniciativas populares especialmente, permiten a los ciudadanos confrontar a los gobernantes con nuevas demandas, cuestionando el monopolio de los políticos profesionales sobre la agenda de gobierno. Estos mecanismos de democracia directa impulsados por los ciudadanos, destaca Altman, «no buscan suplantar la democracia representativa, sino servir como válvulas de escape intermitentes en contra del comportamiento perverso o no-responsivo de las instituciones representativas» ${ }^{35}$. No son instrumentos divisivos, sino genuinos checks and balances políticamente centrípetos, como su práctica revela.

En los lugares donde la iniciativa popular de referéndum existe, la acción legislativa y de gobierno tiende a acercarse más a las preferencias de los votantes que en donde no se reconoce y se incorporan asuntos a la agenda parlamentaria que no figuraban con anterioridad o no eran recogidos por los grupos políticos ${ }^{36}$. Ejemplos de ello se suceden en Massachusetts y en otros Estados de EE.UU., donde las contrapropuestas o alternativas parlamentarias a las iniciativas populares incorporan aspectos de éstas y, por su carácter transaccional, suelen ser preferidas por los ciudadanos. Las iniciativas populares también propician la negociación en California sin siquiera llegar a votarse, puesto que pueden ser retiradas de obtener una acogida satisfactoria por parte de las autoridades. Y similar dinámica consensual se genera en otros Estados en los que se reconoce la iniciativa popular de referéndum, como en Uruguay, los Länder alemanes y Suiza, donde, como señala Sáenz Royo refiriéndose al caso suizo, «cualquier propuesta es debatida antes de su consideración parlamentaria por un amplio sector institucional y social (partidos, cantones y grupos de interés)» a fin de «asegurar que todos los intereses afectados por la nueva regulación - y especialmente los actores capaces de presentar una amenaza creíble de referéndum - tengan la oportunidad de dar su opinión y ser oídos [.... $»$. Y cuando las iniciativas populares ya se han puesto en marcha se abre un proceso de «negociación ex post que puede incorporar parcialmente las demandas o bien directamente en un contraproyecto parlamentario de reforma constitucional o bien indirectamente a través de una modificación legislativa» ${ }^{37}$.

Contraponer la participación popular directa a la representación constituye un falso dilema. En Uruguay, los referéndums de iniciativa popular han servido

35 D. Altman, Direct Democracy Worldwide, Cambridge University Press, New York, 2011, p. 2.

36 E. R. Gerber, «Legislative Response to the Threat of Popular Initiatives», cit., p. 99. Más ampliamente, J. F. Zimmerman, The Initiative: Citizen Lawmaking, cit., pp. 129-155 y R. Enstrom y J. R. DewitT, «Petitioners and Policy Makers: State Legislator Perceptios of Petitioners and Direct Democracy», en S. REYLLY \& R. M. YONK, Direct Democracy in the United States: Petitioners as a Reflection of Society, Routledge, New York, 2013, pp. 92-117.

37 E. SÁEnz Royo, «La regulación y la práctica del referéndum en Suiza: un análisis desde las críticas a la institución del referéndum», REP, n. ${ }^{\circ} 171,2016$, p. 92. 
para consolidar la transición a la democracia y defender el Estado social frente a sus amenazas ${ }^{38}$. En Italia, el referéndum abrogatorio a iniciativa popular es una institución esencial de su sistema político, y su efecto, cuando se logra superar el quórum requerido, ha sido integrador, porque, frente a las iniciativas abrogatorias, los electores han confirmado normalmente la opción legislativa del parlamento, con excepción de los referéndums promovidos durante la crisis del sistema de partidos (1993) o el caso de la consulta contra la energía nuclear, celebrada tras el accidente de Chernóbil (1987) ${ }^{39}$. En Suiza, aproximadamente el 93\% de las leyes susceptibles de referéndum resultan aprobadas por el parlamento y no son cuestionadas por iniciativas abrogatorias. La posibilidad atribuida a los ciudadanos de instar la celebración de referéndums propositivos y derogatorios ha reforzado la negociación en sede parlamentaria ante cualquier propuesta de nueva regulación. Y, cuando se termina votando, incluso entre las iniciativas y los contraproyectos, el supuesto choque entre el pueblo y el parlamento no se ha producido. Ambas legitimidades se han complementado. E idéntica función integradora ha desempeñado la iniciativa popular de referéndum en los Estados norteamericanos en que existe, en los que la mera posibilidad de convocar a consulta al cuerpo electoral estimula el compromiso entre los actores políticos a fin de evitar su activación y, de ser convocada la consulta, proporciona un complemento útil al sistema de gobierno representativo ${ }^{40}$.

\section{LOS INTENTOS DE REGULACIÓN DE LA INICIATIVA POPULAR DE REFERÉNDUM EN ESPAÑA: BALANCE Y PERSPECTIVAS}

Aunque en España la experiencia en materia de democracia directa es muy limitada, no han faltado intentos de institucionalizar constitucionalmente la iniciativa popular de referéndum, en nuestro caso para instar la convocatoria de referéndums de ratificación y/o derogación de textos legislativos. En 1931 fue constitucionalizada la iniciativa popular de referéndum sobre leyes votadas por las Cortes, pero su desarrollo legislativo quedó inédito. La iniciativa popular de referéndum reapareció en el anteproyecto constitucional elaborado por la ponencia en 1978, en esta ocasión vinculada al referéndum derogatorio de leyes. La propuesta encontró el rechazo de la Comisión de Asuntos Constitucionales del Congreso de los Diputados y fue eliminada del articulado constitucional. En el contexto de la reciente crisis de legitimidad de la democracia representativa, el reconocimiento de la iniciativa popular de referéndum ha vuelto a ser planteado

38 En este sentido, R. Altman, Direct Democracy Worldwide, cit., pp. 140-162.

39 G. Rolla, «Las dinámicas entre el referéndum, las instituciones de democracia representativa y los partidos políticos. Consideraciones a la luz de la experiencia italiana», cit., 223.

40 G. Alan TARR, «Direct Democracy in the United States», cit., p. 21. 
en tres proposiciones de reforma constitucional registradas en el Congreso de los Diputados durante la X Legislatura: las dos primeras a instancias del Grupo Parlamentario Mixto y del Grupo de IU, ICV-EUiA, CHA: La Izquierda Plural; la tercera, presentada por la Junta General del Principado de Asturias y todavía hoy pendiente del preceptivo debate de toma en consideración.

\section{La iniciativa popular de referéndum en la Constitución de 1931 y en el anteproyecto constitucional de 1978}

Siguiendo el modelo del constitucionalismo de entreguerras, singularmente la regulación de la democracia directa en la Constitución alemana de Weimar ${ }^{41}$, el constituyente español de 1931 incorporó a nuestro ordenamiento jurídico la iniciativa popular de referéndum de ratificación legislativa. Tanto los diputados socialistas como los de Acción Republicana eran muy reacios a la constitucionalización del referéndum debido a su posible manipulación por minorías, pero su reconocimiento se planteó a través de votos particulares al proyecto. El primero, presentado por J. Castrillo, proponía la inclusión del referéndum a iniciativa, entre otros sujetos legitimados, de los ciudadanos. El segundo, de J. M. ${ }^{a}$ Gil-Robles, preveía, junto al referéndum, la introducción de la iniciativa popular según el modelo de la Constitución alemana. La única de dichas propuestas que fue debatida fue la primera y varios grupos solicitaron que, además del referéndum, se introdujeran otras instituciones de democracia directa. La Comisión rechazó el voto particular de Castrillo, pero aceptó elaborar un nuevo dictamen al que incorporó el referéndum legislativo a iniciativa popular que figuraría casi sin cambios hasta el artículo 66 definitivo, en el que se reconoció al quince por ciento del cuerpo electoral la facultad de «atraer a su decisión leyes votadas por las Cortes que no fueran complementarias de la Constitución, leyes de ratificación de convenios internacionales inscritos en la Sociedad de Naciones, estatutos regionales o leyes tributarias, en los términos que fijara una ley especial» ${ }^{42}$. Pese a su constitucionalización, la ley especial de desarrollo no fue aprobada durante la Segunda República y, consecuentemente, ninguna iniciativa popular de referéndum de ratificación legislativa se puso en marcha.

Tras el largo período de dictadura franquista, el anteproyecto de Constitución elaborado por la Ponencia recuperó la iniciativa popular de referéndum, atribuyendo la iniciativa para someter a votación la derogación de leyes en vigor no

41 Sobre la influencia de la regulación en materia de referéndum contenida en el artículo 73.2 y 3 de la Constitución de Weimar en el constituyente español de 1931, M. A. Presno Linera, «El referéndum en la Constitución española: límites y posibles reformas», E. SÁEnz Royo y C. GARrido López (coords.), $L a$ funcionalidad del referéndum en la democracia representativa, cit., pp. 52-53.

42 Sobre el tema, N. PÉrez Serrano, La Constitución española, Editorial Revista de Derecho Privado, Madrid, 1932, p. 243. 
sólo al Gobierno, a cualquiera de las Cámaras y a tres asambleas de territorios autónomos, sino también a 750.000 electores en las condiciones que regulara una ley orgánica (art. 85). Los ponentes, previeron, asimismo, el referéndum sobre decisiones políticas de especial trascendencia y el referéndum sobre leyes votadas por las Cortes Generales y aún no sancionadas, aunque en ambas modalidades limitaron su iniciativa al Gobierno, a cualquiera de las Cámaras y a tres asambleas autonómicas, excluyendo la iniciativa popular ${ }^{43}$. La regulación de la democracia directa contenida en el anteproyecto era, pese a esta exclusión, generosa y podría haber prosperado. Como es sabido, sin embargo, en la tramitación parlamentaria posterior del texto constitucional se exageraron los peligros de la participación a través del referéndum y de la iniciativa popular, se cuestionó su legitimidad y funcionalidad democráticas y se minusvaloró su rendimiento en el Derecho comparado.

En el recelo del constituyente hacia la democracia directa pesaron el uso instrumental y plebiscitario que del referéndum hizo el régimen franquista, así como las recientes experiencias francesa e italiana, consideradas poco satisfactorias. En Francia, el general De Gaulle había usado al referéndum para fortalecer su liderazgo eludiendo al Parlamento, y en Italia el reconocimiento de la iniciativa popular para convocar referéndums abrogatorios había provocado fuertes tensiones políticas, en 1974 con ocasión del divorcio y en junio de 1978 con la ley sobre financiación de los partidos políticos. Junto a estos factores, también se hizo presente una específica concepción del parlamentarismo patrocinada por los grupos mayoritarios: un parlamentarismo - en palabras de Garrorena Morales«bastante puro, es decir, celoso a la hora de preservar la primacía institucional de Parlamento y, a su través, la de una clase política muy refractaria a cualquier recorte en su recién estrenada posición ${ }^{44}$. Como resultado, la iniciativa popular de referéndum desapareció del texto constitucional y los referéndums legislativos, tanto abrogatorios cuanto sobre leyes votadas y aún no sancionadas, fueron descartados de la redacción final ${ }^{45}$.

43 BOCG, n. ${ }^{\circ} 44,5$ de enero de 1978, p. 683.

44 A. Garrorena Morales, El Estado español como Estado social y democrático de Derecho, Tecnos, Madrid, 1984, p. 146. Más ampliamente, sobre las razones que determinaron la restricción de las modalidades de referéndum y de su iniciativa durante el proceso constituyente, M. Ramírez Jiménez, La participación política, Tecnos, Madrid, 1985, pp. 55-56 y J. Oliver Araujo: «El referéndum en el sistema constitucional español», REP, n. ${ }^{\circ} 29,1989$, pp. 134-140.

45 En defensa de la enmienda «in voce» cuya aceptación por la Comisión de Asuntos Constitucionales y Libertades Públicas modificó la redacción del artículo 85 del anteproyecto constitucional, el diputado Solé Tura señaló que el referéndum sobre leyes aprobadas aún no sancionadas abriría «la extraña posibilidad de que la soberanía del Parlamento fuera absolutamente menoscabada» y posibilitaría la aparición de conflictos entre el Gobierno, el Rey y el Parlamento, interfiriendo extraordinariamente en todo el proceso legislativo normal. «En cuanto al referéndum derogatorio — continuó — se presta, como sabemos, en la práctica política a muchas y contradictorias utilizaciones; de modo que es también dudoso que se pueda calificar sin más de práctica democrática. Puede ser precisamente lo contrario, y ejemplos no faltan, de que sea una de las formas precisamente de impedir una labor democrática desde el máximo órgano legislativo» (DSCD, n. ${ }^{\circ} 81$, Comisión de 
El constituyente se limitó a regular los referéndums preceptivos de revisión constitucional (art. $168 \mathrm{CE}$ ) y de ratificación de la iniciativa autonómica, de aprobación y reforma de determinados Estatutos de Autonomía y de ratificación de una hipotética incorporación de Navarra al País Vasco (arts. 151.1, 151.2.3. ${ }^{\circ}$ y 152.2 y DT $4 .{ }^{a} \mathrm{CE}$, respectivamente), el referéndum de reforma constitucional a petición de una décima parte de diputados o senadores (art. 167 CE) y el referéndum consultivo sobre decisiones políticas de especial transcendencia a iniciativa del Presidente del Gobierno (art. $92 \mathrm{CE}$ ). Debido a su restrictiva regulación — que la deficiente Ley Orgánica 2/1980, de 18 de enero, sobre regulación de las distintas modalidades de referéndum (LOMR), agudizó- y al recelo de la clase política, la práctica del referéndum ha sido excepcional. Además de los referéndums de ratificación de la iniciativa autonómica de Andalucía y de aprobación y reforma de los Estatutos de Autonomía elaborados conforme al artículo 151.2 CE, sólo se han celebrado dos referéndums nacionales a iniciativa del presidente del Gobierno: el referéndum de 12 de marzo de 1986 sobre la permanencia de España en la OTAN y el referéndum de 20 de febrero de 2005 de ratificación del tratado que instituía una Constitución para Europa. Sin duda, un balance muy pobre.

\section{La iniciativa popular de referéndum en las proposiciones de reforma constitucional de la X Legislatura: en especial, la regulación contenida en la proposición de la Junta General del Principado de Asturias}

En el contexto de grave crisis que, desde 2009, afectó en España a la democracia representativa, resurgió con fuerza el debate en torno a la conveniencia de impulsar el ejercicio de la democracia directa incorporando a nuestro ordenamiento nuevas modalidades de referéndum, como el referéndum sobre leyes en vigor o el referéndum propositivo, y reconociendo a un número o un porcentaje de ciudadanos la facultad de solicitar su celebración. A este respecto, la recesión económica y la subsiguiente crisis política operó como una poderosa lupa sobre las carencias y los defectos de nuestras instituciones representativas, que habían sido contemplados con indulgencia o indiferencia en tiempos de bonanza, pero que resultaban

\footnotetext{
Asuntos Constitucionales y Libertades Públicas, sesión de 6 de junio de 1978, pp. 2937). Sumándose a las tesis de Solé Tura, el centrista Pérez-Llorca arguyó, tanto en el debate en Comisión como en el posterior debate en el Pleno, que el referéndum sobre leyes votadas y aún no sancionadas podía convertirse en una especie de veto plebiscitario «cuya introducción en la Constitución, unida a la iniciativa popular, podría dejar en manos de minorías fuertemente organizadas la suerte de leyes debatidas en las Cámaras, e incluso la suerte de esas propias Cámaras. E igualmente cierto es, a mi juicio —abundó—, que el referéndum abrogatorio, unido a la iniciativa popular, podría plantear, en este momento inaugural del sistema constitucional en España, conflictos gravísimos. Y ésta es una cuestión política que no podemos eludir, ya que podrían ser planteados por minorías, por grupos extraparlamentarios minoritarios, y en ciertas cuestiones concretas podrían crear conflictos graves al funcionamiento adecuado del sistema» (DSCD, n. ${ }^{\circ} 81$, Comisión de Asuntos Constitucionales y Libertades Públicas, 6 de junio de 1978, p. 2940, y DSCD, n. ${ }^{\circ}$ 109, Pleno, 13 de julio de 1978, pp. 4213.
} 
intolerables cuando dichas instituciones adoptaron decisiones económicas críticas socialmente regresivas e impopulares. Debilitado el idem sentire entre representantes y representados, interrumpida la suspensión voluntaria de la incredulidad en que se asienta el dogma de la representación política ${ }^{46}$, muchos ciudadanos reclamaron nuevas vías de participación que les permitieran incidir efectivamente en el proceso de formación de la voluntad general. Y así lo hicieron llegar a las instituciones a través de peticiones colectivas, asociaciones y partidos políticos, desde que la indignación que cristalizó el 15 de mayo de 2011 en las plazas de las principales ciudades españolas sirviera de catalizador de diversas demandas de regeneración democrática $^{47}$. El impuso de la iniciativa popular fue una de esas vías de participación. Una iniciativa popular que algunos de los Estatutos de Autonomía reformados acababan de incorporar a su articulado, legitimando a los ciudadanos para instar la celebración de consultas populares autonómicas y locales — no referendarias, según ha interpretado el Tribunal Constitucional (en especial, SSTC 31/2015 y 137/2015)_en su ámbito territorial ${ }^{48}$. Recogiendo estas demandas a escala nacional, en los últimos años se han sucedido varias propuestas para impulsar constitucionalmente el

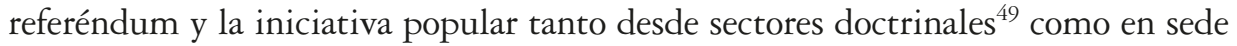

46 Sobre la idea de la suspensión voluntaria de la incredulidad como fundamento del gobierno representativo, E. S. Morgan, La invención del pueblo. El surgimiento de la soberanía popular en Inglaterra y los Estados Unidos, Siglo xxi, Buenos Aires, 2006, pp. 13-14.

47 Un análisis de los postulados y propuestas programáticas de impulso democrático del llamado movimiento 15-M en M. A. Presno Linera, El 15-M y la promesa de la política, Agenda Pública, 2013. Disponible en: http://www.accionenredasturies.org/upload/20140211223341_0.pdf.

48 Reconocen el derecho de los ciudadanos a promover la convocatoria de consultas populares autonómicas y locales en los términos previstos por la CE y las leyes (y, evidentemente, en los términos de la jurisprudencia interpretativa del Tribunal Constitucional sobre la materia) los Estatutos de Autonomía de Andalucía (art. 30.1.c), Castilla y León (art. 11.5), Cataluña (art. 29.6) e Islas Baleares (art. 15.c) y, tras la aprobación de la Ley Orgánica 1/2018, de 5 de noviembre, de reforma de su Estatuto de Autonomía, también Canarias (art. 31.e). Cataluña ha regulado esta facultad de iniciativa ciudadana en el artículo 35 de la Ley 10/2014, de 26 de septiembre, de consultas populares no referendarias y otras formas de participación ciudadana, recociéndola a 75.000 personas de las llamadas a participar, en el ámbito autonómico, y a un porcentaje variable de vecinos llamados a participar en función de la población, en el ámbito local. Con anterioridad, el Parlament reguló la iniciativa popular de referéndum en los artículos 21 a 30 de la Ley 4/2010, de 17 de marzo, de consultas populares por vía de referéndum, pero la STC 31/2010 (FJ 69) privó de base estatutaria a la Ley y la STC 51/2017 declaró la inconstitucionalidad de su título II (arts. 10 a 30). Andalucía regula la iniciativa ciudadana para instar la celebración de consultas populares en los artículos 45 y 48 de la Ley 7/2017, de 27 de diciembre, de Participación Ciudadana de Andalucía, reconociéndola a 30.000 personas con derecho a participar, en el ámbito autonómico, y a un porcentaje variable atendiendo a la población, en el ámbito local. En Baleares y Castilla y León están en trámite sendos proyectos de ley que pretenden regular dicha iniciativa: el Proyecto de ley RGE 8321/2018, de consultas populares y procesos participativos, aprobado por el Consell de las Islas Baleares el 27 de julio de 2018, y el Proyecto de Ley de diálogo civil de Castilla y León, aprobado por el Consejo de Gobierno el 6 de septiembre de 2018.

49 En el ámbito académico destacan los trabajos de M. Á. Presno Linera, «La democracia directa y la falacia de sus riesgos», I. GUTIÉRREZ GutiÉRreZ (coord.), La democracia indignada: tensiones entre la voluntad popular y representación política, Comares, Granada, 2014, pp. 61-92; P. REQUEJO RodRíGUEZ, «El referéndum consultivo en España: reflexiones críticas y algunas propuestas de futuro», Estudios de Deusto, vol. 62/1, 2014, pp. 261-284; E. Vírgala ForURia, «Representación, parlamentarismo y democracia participativa», en M. A. García Herrera, J. Asensi Sabater y F. Balaguer Callejón (coords.), Constitucionalismo crítico. Liber amicorum Carlos de Cabo Martín, Tirant lo Blanch, Valencia, 2015, pp. 1055-1083; E. SÁenz Royo, «La 
parlamentaria, donde se han registrado varias proposiciones de reforma constitucional que incluían en su articulado la iniciativa popular de referéndum.

La primera de las proposiciones de reforma constitucional que propugnaba el reconocimiento de la iniciativa popular de referéndum fue presentada por el Grupo Parlamentario Mixto y el Grupo de IU, ICV-EUiA, CHA: La Izquierda Plural el 31 de enero de 2012, pero fue retirada el 14 de mayo de $2013^{50}$. Un día antes de esta retirada, el 13 de mayo de 2013, los mismos grupos presentaron con idéntico contenido una segunda proposición de reforma constitucional. Justificada en la referida crisis de legitimidad de la democracia representativa, la proposición tenía por objeto impulsar la proporcionalidad del sistema electoral y la participación política directa mediante la reforma de los artículos 68, 69, 87.3, 92 y 167 CE. En el ámbito de la democracia directa, sus signatarios pretendían eliminar los límites materiales de la iniciativa legislativa popular, extender el referéndum preceptivo a toda reforma constitucional y ampliar tanto los ámbitos territoriales en los que sería posible su celebración como los sujetos legitimados para instar la convocatoria de referéndums sobre asuntos de especial relevancia e interés para la ciudadanía. Dichos referéndums, en materias de competencia estatal, serían convocados por el Rey, previa autorización del Congreso, «a petición de un cinco por ciento de miembros del Congreso o del Senado y a iniciativa popular con los requisitos exigidos para las iniciativas legislativas populares». En materias de competencia autonómica, los presidentes de las CCAA podrían convocar referéndum «a petición de sus asambleas o a iniciativa popular, de acuerdo con el procedimiento establecido en las leyes autonómicas». Y sobre asuntos de interés local, también los alcaldes o presidentes de las entidades locales podrían convocar referéndums consultivos, a petición de sus plenos o a iniciativa popular, en los términos que regulara la legislación básica sobre régimen local ${ }^{51}$. La proposición de reforma constitucional fue admitida a trámite por la Mesa del Congreso el 21 de mayo de 2013, pero caducó al disolverse las Cámaras sin ser tomada en consideración por el Pleno ${ }^{52}$.

regulación del referéndum en el Derecho comparado: aportaciones para el debate en España», REDC, n. ${ }^{\circ} 108$, 2016, pp. 123-153; J. M. a CASTELlà ANDreu, «El referéndum en la Constitución: ¿es necesario un replanteamiento de la institución?», en J. L. Cascajo Castro y A. Martín De La Vega (coords.), Participación, representación y democracia, Tirant lo Blanch, Valencia, 2016, pp. 235-266; F. J. DíAz Revorío, «Democracia, representación y participación ciudadana. A la búsqueda de un equilibrio que la Constitución no logró», RDP , n. ${ }^{\circ}$ 101, 2018, pp. 239-270; y J. M. ${ }^{a}$ Morales Arroyo, «El alcance y los límites de los instrumentos constitucionales de participación directa», Revista General de Derecho Constitucional, n. ${ }^{\circ}$ 26, 2018, disponible en: https://www.iustel.com/v2/revistas/detalle_revista.asp? $i d=3 \&$ numero $=26$.

50 La primera proposición de reforma constitucional «para reforzar la participación política y el pluralismo en el régimen electoral» puede verse en el BOCG, CD, Serie B, n. ${ }^{\circ}$ 55-1, de 10 de febrero de 2012. Su retirada se publicó en $B O C G, C D$, Serie $\mathrm{B}, \mathrm{n}^{\circ}$ 55-2, de 20 de mayo de 2013.

51 BOCG, CD, Serie B, n. ${ }^{\circ}$ 122-1, 24 de mayo de 2013, pp. 1-4. Un análisis de esta proposición de reforma constitucional en P. REQUEJO RODRÍGUEZ, «El referéndum consultivo en España: reflexiones críticas y algunas propuestas de futuro», cit., pp. 276-277.

52 BOCG, CD , n. ${ }^{\circ} \mathrm{D}-758,20$ de noviembre de 2015, p. 4. Unos meses antes del registro de esta proposición de reforma constitucional, los mismos grupos parlamentarios pretendieron, también infructuosamente, la modificación de la LOMR. En efecto, tras el anuncio realizado por el Presidente del Gobierno, Mariano Rajoy, 
La tercera propuesta de reforma constitucional de las formas de democracia directa fue presentada en el Congreso de los Diputados por la Junta General del Principado de Asturias el 16 de octubre de 2014. Dotada de mayor calidad técnica que la proposición de reforma constitucional presentada por los Grupos Parlamentarios Mixto y de la Izquierda Plural, esta singular iniciativa autonómica, que propugna la reforma de los artículos 87.3, 92 y $166 \mathrm{CE}$, traía causa del manifiesto «Por la democracia directa», presentado al amparo del derecho de petición reconocido en el artículo $29 \mathrm{CE}$ por varias miles de ciudadanos ante varios parlamentos autonómicos. En Asturias, la petición fue respaldada por 7.700 personas y se registró en la Junta General del Principado en diciembre de 2011. Un año más tarde, el Grupo Parlamentario de Izquierda Unida en la Junta General del Principado asumió la propuesta ciudadana formalizándola parlamentariamente a través de una propuesta de proposición de las del artículo $166 \mathrm{CE}$, en relación con el artículo 87.2 de la misma ${ }^{53}$. En la propuesta inicial, que fue tomada en consideración por la cámara asturiana el 24 de mayo de $2013^{54}$, se pretendían eliminar los límites materiales a la iniciativa legislativa popular previstos en el artículo 87.3 CE, reconocer a 500.000 ciudadanos la facultad de promover una reforma constitucional, incorporar a la CE la figura del referéndum sobre leyes votadas por las Cortes y aún no sancionadas y la del referéndum legislativo derogatorio en parecidos términos a los del artículo 75 de la Constitución italiana y ampliar la facultad de iniciativa de referéndum sobre cuestiones políticas de especial trascendencia, sobre leyes votadas y aún no sancionadas y sobre derogación de leyes en vigor a ambas Cámaras, a las asambleas de tres CCAA y a 500.000 electores, es decir, constitucionalizar para tres modalidades referendarias la iniciativa popular de referéndum en nuestro país. El resultado, en cualquiera de las tres modalidades, sería vinculante cuando participaran en la votación la mayoría de quienes tuvieran derecho a hacerlo y hubiera sido aprobado por mayoría de los votos válidamente emitidos.

A la propuesta de nueva redacción del artículo 92 CE contenida en la proposición inicial se presentaron tres enmiendas. La del Grupo Foro Asturias pidió la

en el Congreso de los Diputados de nuevos ajustes y recortes sociales para reducir el gasto público anual en 65.000 millones de euros, el GP Mixto y el Grupo de IU, ICV-EUiA, CHA: La Izquierda Plural presentaron conjuntamente el 18 de julio de 2012 una proposición de ley orgánica que pretendía introducir en el artículo 6 de la LOMR la obligatoriedad de convocatoria de un referéndum cuando las decisiones políticas a adoptar afectaran sustancialmente a derechos económicos, sociales y laborales (vid. BOCG, CD, Serie B, n. ${ }^{\circ}$ 91-1, 27 de julio de 2012, pp. 1-2.). La proposición de ley fue rechazada, pero dio lugar a un interesante debate parlamentario el 27 de noviembre de 2012, en el trascurso del cual se criticó que los proponentes pretendieran modificar el carácter facultativo del referéndum previsto en el artículo $92 \mathrm{CE}$ a través de una mera ley orgánica. Las intervenciones en dicho debate pueden verse en DSCD, n. ${ }^{\circ} 75,27$ de noviembre de 2012, pp. 18-37.

53 BOJGPA, Serie A, n. ${ }^{\circ}$ 16.1, de 12 de diciembre de 2012. Un análisis de la gestación y del contenido de la proposición en M. A. Presno Linera, «Propuesta de reforma de la Constitución para promover la participación ciudadana», en https://presnolinera.wordpress.com/2014/02/17/propuesta-de-reforma-de-la-constitucion-para-promover-la-participacion-ciudadana/ (consultado el 10 de marzo de 2018).

54 El debate de toma en consideración puede verse en el DSJGPA, Serie P, n. ${ }^{\circ}$ 60, 24 de mayo de 2013 , pp. 5-16. 
supresión, al rechazar de plano «la pretensión de instaurar, con carácter obligatorio, la celebración de un referéndum [...] con la mera solicitud de 500.000 electores», lo que a su juicio podría reemplazar la democracia representativa por una democracia populista. Las enmiendas del Grupo Parlamentario Socialista y del diputado del Grupo Mixto, perteneciente al partido Unión, Progreso y Democracia, que habían votado a favor de la toma en consideración de la proposición, pretendían básicamente excluir del artículo el referéndum sobre leyes votadas y aún no sancionadas, reconocer la legitimación para solicitar la celebración de referéndums abrogatorios sólo a los ciudadanos y vetar el ejercicio de esta iniciativa popular en materias tributarias, presupuestarias, de carácter internacional y en lo relativo a la prerrogativa de gracia. Ambas enmiendas, por tanto, pretendían aproximar la redacción de la proposición a la regulación de la iniciativa y del referéndum contenida en el artículo 75 de la Constitución italiana. La ponencia designada por la Comisión de Presidencia de la Junta General rechazó la enmienda del Grupo Foro Asturias y redactó un texto transaccional que dio lugar a la retirada de las enmiendas del Grupo Socialista y del Grupo Mixto ${ }^{55}$. Fruto de esta transacción resultó una nueva propuesta de redacción para el artículo $92 \mathrm{CE}$ que fue debatida y aprobada por la Comisión de Presidencia el 17 de febrero de 2014 y por el Pleno de la Junta General del Principado el 24 de mayo del mismo año, con los votos a favor de los Grupos Parlamentarios Socialista, de Izquierda Unida y Mixto y los votos en contra de los Grupos Popular y Foro Asturias ${ }^{56}$.

En su redacción definitiva, la proposición de reforma constitucional del artículo 92 CE de la Junta General del Principado de Asturias distingue entre el plebiscito y el referéndum sobre derogación de leyes en vigor. El primero, así denominado según los proponentes por tratarse de una consulta sobre cuestiones políticas cuyo resultado no sería jurídicamente vinculante ${ }^{57}$, versaría sobre decisiones políticas de especial trascendencia y podría ser convocado a propuesta del presidente del Gobierno, autorizada por el Congreso de los Diputados, o a iniciativa popular de 500.000 electores. Con la ampliación de la legitimación para instar la convocatoria del actual referéndum consultivo sobre decisiones políticas, la proposición persigue privar del monopolio de la iniciativa al presidente del Gobierno y evitar que su convocatoria dependa de la mayoría parlamentaria. La razón es clara: cuando los gobiernos y las mayorías parlamentarias controlan el referéndum tienden a usarlo cuando esperan ganar, a fin de reforzar su poder y

55 El informe de la ponencia puede verse en el BOJPA, Serie A, n. ${ }^{\circ} 16.11$, de 3 de julio de 2014.

56 Los debates celebrados en la Comisión pueden verse en DSJGPA, Serie C, n. ${ }^{\circ} 213$, de 17 de febrero de 2014, pp. 18-24 y los celebrados en el Pleno en DSJGPA, Serie P, n. ${ }^{\circ}$ 60, de 24 de mayo de 2014, pp. 5-15 y n. ${ }^{\circ} 37$, de 19 de septiembre de 2014, pp. 5-16.

57 Con esta distinción, la Junta General del Principado asume la corriente doctrinal que reserva la expresión «plebiscito» para los pronunciamientos del cuerpo electoral en relación con una decisión política o medida de gobierno, reservando la denominación de referendo para la «manifestación del cuerpo electoral respecto a un acto normativo». Cfr. P. Biscaretti Du Ruffia, Derecho Constitucional, Tecnos, Madrid, 1982, p. 425. Esta distinción, sin embargo, es puramente académica y no mayoritaria. 
eliminar resistencias y contrapesos ${ }^{58}$. Ampliar la legitimación a los ciudadanos, en cambio, compensa esa tentación, arrumba el monopolio del plebiscito y suma un poder corrector al sistema, al posibilitar el planteamiento de cuestiones que los detentadores del poder rechazan consultar o directamente ignoran. Otorgando todavía mayor protagonismo a la participación política directa vía iniciativa ciudadana, la proposición pretende incorporar a nuestro sistema constitucional el referéndum derogatorio de leyes en vigor, jurídicamente vinculante, que, al igual que en el ordenamiento constitucional italiano, sólo podría ser convocado a iniciativa popular, atribuida a un mínimo de 500.000 electores. Esta iniciativa popular tendría límites materiales similares a los previstos en el Derecho comparado $^{59}$, no pudiendo versar sobre materias tributarias, presupuestarias o de carácter internacional, ni sobre la prerrogativa de gracia. Y el resultado del referéndum derogatorio instado popularmente sólo sería vinculante de superar el quórum de participación de la mayoría de electores inscritos en el censo, como se prevé en Italia y en varios Länder alemanes, y cuando resultara aprobado por mayoría de los votos válidamente emitidos. Por economía electoral, tanto los plebiscitos como los referéndums deberían celebrarse en la misma fecha que los procesos electorales de ámbito nacional que coincidieran en el mismo año.

Concluida su tramitación, la proposición fue remitida al Congreso de los Diputados, siendo admitida a trámite el 21 de octubre de $2014^{60}$. Durante un año, sin embargo, los órganos de gobierno de la Cámara demoraron su toma en consideración. Tras la disolución de las Cortes Generales en octubre de 2015, la proposición de reforma constitucional fue trasladada al Congreso de la XI Legislatura $^{61}$. Y tras la nueva disolución de las Cámaras en cumplimiento de las previsiones del artículo 99.5 CE y las elecciones generales de 24 de junio de 2016, fue trasladada al Congreso de los Diputados de la XII Legislatura ${ }^{62}$.

\section{La reactivación de los prejuicios y las cautelas hacia la democracia directa}

En este nuevo contexto caracterizado por los intentos de regeneración política y de preocupación por la mejora de la calidad democrática, las actitudes de recelo de la doctrina y de la clase política hacia las formas de participación política directa parecían estar cambiando y no era descabellado prever que, con un

58 A. Lijphart, Democracies: Patterns of Majoritarian and Consensus Government in Twenty-One Countries, Yale University Press, New Haven, 1984, p. 204.

59 Sobre los límites o exclusiones materiales de la iniciativa popular de referéndum en el Derecho comparado, C. Garrido López, «El debate sobre los riesgos y los límites del referéndum en perspectiva comparada», en E. SÁEnz Royo y C. GARrido López (coords.), La funcionalidad del referéndum en la democracia representativa, cit., pp. 223-227.

60 BOCG, CD, Serie B, n. ${ }^{\circ}$ 194-1, 24 de octubre de 2014, pp. 1-3.

61 BOCG, CD, n. ${ }^{\circ} \mathrm{D}-758,20$ de noviembre de 2015, p. 1473.

62 BOCG, CD, Serie B, n. ${ }^{\circ} 1-1,9$ de septiembre de 2016, pp. 1-3. 
significativo cambio en la correlación de fuerzas parlamentarias, como el que se produjo tras las elecciones generales de diciembre de 2015 y de junio de 2016, la proposición de reforma constitucional de la Junta General del Principado de Asturias podía llegar a ser, al menos, tomada en consideración. No en vano, varios de los principales partidos políticos incorporaban en sus programas electorales compromisos de impulso democrático y fomento de la participación política $^{63}$. Dos años después, sin embargo, la proposición de reforma constitucional sigue siendo ignorada por la Mesa de la Cámara, lo que está frustrando no pocas expectativas, además de suponer un lamentable desprecio hacia una iniciativa de singular alcance de un parlamento autonómico, presentada nada menos que al amparo del artículo 166.1 CE, en conexión con su artículo 87.2.

A nuestro juicio, esta actitud de la Mesa, convalidada por el silencio de los grupos parlamentarios, ha venido determinada por la concurrencia simultánea de dos factores que han reactivado los prejuicios y las cautelas políticas hacia la democracia directa.

El primer factor ha consistido en la sucesión de referéndums en varios países europeos cuya convocatoria y resultados han sido extraordinariamente polémicos, como el referéndum sobre las condiciones del tercer rescate de la economía griega, el brexit británico, los referéndums sobre las cuotas de refugiados y sobre el acuerdo de cooperación entre la UE y Ucrania celebrados, respectivamente, en Hungría y Países Bajos o el referéndum de reforma constitucional en Turquía ${ }^{64}$. A resultas de todos ellos, se ha desatado un alu-

63 En este sentido, pueden verse los programas electorales para las elecciones generales del 20 de diciembre de 2015 de PSOE, El cambio que une, p. 89, y de Ciudadanos, El nuevo proyecto común para España, p. 6. Y más explícitamente, a favor del impulso constitucional de los referéndums, la iniciativa popular y las consultas populares, los programas electorales de Podemos, Queremos, sabemos, podemos, pp. 157-158, de Izquierda Unida-Unidad Popular, Por un nuevo país, p. 18, y de Unión, Progreso y Democracia, Más España, p. 10. Todos disponibles en https://www.lasprovincias.es/elecciones/generales/201512/09/programa-electoral-psoe-para-20151209104152.html.

64 El 5 de julio de 2015, el primer ministro griego, A. Tsipras, sometió a referéndum, con un plazo de campaña de sólo cinco días y una pregunta claramente sesgada, el plan de recortes exigido por la UE, el Banco Central Europeo y el Fondo Monetario Internacional, con el único objeto de reforzar plebiscitariamente su débil posición negociadora. El 5 de abril de 2016, se celebró en los Países Bajos un referéndum a iniciativa popular al amparo de la ley de referéndum consultivo (Wet raadgevend referéndum), aprobada en 2015 . El objeto de la consulta fue el acuerdo de asociación suscrito entre Ucrania y la UE que ya había sido ratificado por ambas cámaras del Parlamento nacional; y pese a la campaña a favor del Gobierno y de las principales fuerzas políticas, el acuerdo fue rechazado por una mayoría de votantes en abierto desafío a los compromisos de la UE. El 23 de junio de 2016, el gobierno británico sometió a referéndum la permanencia del Reino Unido en la UE, en las condiciones renegociadas con la propia UE, o su salida de la UE, y, contra pronóstico, triunfó el Brexit, esto es la salida de la UE, desencadenando con ello un terremoto político de imprevisibles consecuencias. El 2 de octubre de 2016, los húngaros, impulsados por su propio gobierno, rechazaron la cuota de refugiados solicitantes de asilo asignada a Hungría en la Decisión (UE) 2015/1601 del Consejo de 22 de septiembre de 2015, aunque el referéndum no superó el quórum del $50 \%$ de participación requerido por la Ley Fundamental de 2011 para que el resultado fuera considerado válido. Y el 16 de abril de 2017, bajo un estado de emergencia declarado, con algunas libertades públicas limitadas y con los medios de comunicación bajo supervisión del Gobierno, se celebró el referéndum de reforma constitucional en Turquía, donde el presidente Erdogan ha logrado el aval de un 51,3\% de los votantes para transformar el sistema parlamentario en otro presidencialista, aumentando sus poderes y limitando los controles y garantías democráticas. 
vión de críticas contra el referéndum como método válido para la adopción de decisiones colectivas. Para muchos, la proliferación de consultas directas pone en riesgo la estabilidad de nuestros delicados sistemas democráticos y cuestiona los principios de solidaridad y respeto a las libertades que sustentan el proyecto europeo. Los referéndums, afirmó Urquizu, son instrumentos de manipulación política y de evasión de responsabilidades, empobrecen el proceso deliberativo y debilitan a los representantes electos ${ }^{65}$. En opinión de Laporta, consultar al pueblo y a iniciativa del pueblo «es un método de toma de decisiones temerario, confuso y simple que $[\ldots]$ acaba por generar un veredicto político deformado por la ignorancia, la información sesgada y la alteración emocional» ${ }^{66}$. Y contundente, Maravall sentenció que «en sociedades grandes y complejas con intereses heterogéneos, la única democracia posible es la representativa: el vínculo directo entre gobernantes y pueblo no es democrático» ${ }^{67}$.

Es indudable que en los referéndums citados los votantes decidieron en contra de las opciones consideradas obviamente correctas por las élites europeas. De ahí las críticas. Pero ello no justifica que esos referéndums sean tildados de equivocación o fracaso de la democracia, ni resulta admisible atribuir la decisión mayoritaria resultante en estos casos a la ignorancia, la manipulación o la irracionalidad de los votantes. Recuperar estos argumentos contra el referéndum y la iniciativa popular es un error, porque los mismos también pueden emplearse $-\mathrm{y}$ se han empleado en el pasado- contra la ampliación del sufragio y contra las elecciones en las que se sustenta la legitimidad de la democracia representativa. Y también se pueden usar contra la propia democracia parlamentaria. La manipulación, la simplificación y el abuso de las mayorías pueden hacerse presentes en los procesos electorales y en el seno de las instituciones representativas. Como ha señalado Ovejero, «muchos argumentos aducidos contra los referendos descalificarían también a las democracias: toda votación, incluidas las parlamentarias, al final, es dicotómica: sí/no; los parlamentarios padecen sesgos cognitivos o informativos; la manipulación estratégica es una posibilidad y hasta un hábito parlamentario; y la incompetencia agregada de los votantes no es inferior a la de los representantes» ${ }^{68}$. ¿Prescindimos de los parlamentos - como pretende prescindirse del referéndum y la iniciativa popular- por los abusos en los que mayorías arbitrarias $(v, g r$. los actuales parlamentos de Hungría y Polonia) pueden incurrir? ¿Y de las elecciones, por los resultados supuestamente errados que en ellas pueden obtenerse ( $v$. gr. Donald Trump)? No parece el camino más adecuado ${ }^{69}$. Como subraya A. Tarr, «[...] democracy rests on

65 I. Urquizu, «¿El referéndum como solución?», Piedras de Papel, 26 de octubre de 2014. Disponible en: https://www.eldiario.es/piedrasdepapel/referendum-solucion_6_305929428.html.

66 F. J. Laporta, «Contra el referéndum», El País, 31 de octubre de 2016.

67 J. M. Maravall, «Populismos y representación», El País, 21 de febrero de 2017.

68 F. Ovejero, «¿Democracias para niños?», El País, 19 de diciembre de 2016.

69 En la academia, sin embargo, alguna doctrina ya transita por este camino con argumentos ultraelitistas. B. CAPlan (El mito del votante racional: Por qué las democracias escogen malas políticas, Inisfree, Madrid, 2016) sostiene que no podemos esperar mucho de unos votantes inevitablemente irracionales, entregados a 
the assumption that voters are capable of choosing wisely among candidates. Critics therefore must explain why voters' capacity to select policies in referendum is dramatically less than their ability to choose candidates ${ }^{70}$.

El segundo factor que dificulta la toma en consideración de las propuestas de reforma constitucional de la democracia directa es puramente nacional y tiene que ver con el colapso de nuestra peculiar singladura autonómica, donde las pretensiones nacionalistas de secesión territorial vía referéndum, manifestadas en el País Vasco mediante el Plan Ibarretxe y, recientemente, con inusitada intensidad, en Cataluña, han desbordado las previsiones más pesimistas y están amenazando seriamente la continuidad de nuestro modelo de Estado. Estos intentos de secesión, que pretenden legitimarse mediante el voto ciudadano, contaminan y condicionan el debate sobre la democracia directa en nuestro país por las facilidades que, supuestamente, encontrarían los partidos y asociaciones independentistas para impulsar iniciativas populares de referéndums de secesión en su ámbito territorial, o incluso fuera de él, en el caso de producirse un impulso constitucional de la institución. El temor es comprensible políticamente, pero resulta jurídicamente infundado porque, como ha subrayado el TC, «nota común al régimen jurídico-constitucional de las modalidades de referéndum de ámbito infraestatal que se reconocen en los ordenamientos de nuestro entorno es la de que deben tener siempre como objeto, incluso aunque revistan naturaleza consultiva, materias o asuntos de la competencia del Land o región correspondiente, de tal forma que sus efectos se proyecten solo sobre el ámbito del Land o región y sus instituciones ${ }^{71}$. Ninguna iniciativa popular de referéndum autonómico, y tampoco de referéndum nacional, podría tener por objeto la secesión territorial. Y si, pese a todo y desbordando sus límites, dicha iniciativa se impulsara, hallaría el freno del procedimiento de control previo y de admisibilidad de la iniciativa popular que el legislador habría instituido. Un control de admisibilidad que es preceptivo en el Derecho comparado y que se atribuye a la justicia constitucional o a los órganos de garantías electorales ${ }^{72}$.

sesgos que les impiden reconocer factores como el beneficio del comercio o de la inmigración. Por su parte, J. Brennan (The Ethics of Voting, Princeton University Press, Princeton, 2012) propone reconsiderar el derecho al voto de los ciudadanos con menos luces o virtudes. En parecido sentido se pronuncian Ch. ACHEN y L. BARTELS (Democracy for Realists, Princeton University Press, Princeton, 2016); y D. VAN Reydrouck (Contra las elecciones. Cómo salvar la democracia, Taurus, Barcelona, 2017) aboga directamente por sustituir las elecciones por el sorteo como método para salvar la democracia.

70 G. A. TARR, «Direct Democracy in the United States», cit., p. 19.

71 STC 51/2017, de 10 de mayo, fundamento jurídico 4.

72 Existe en el Derecho comparado un riguroso control de admisibilidad de la iniciativa popular previo a la convocatoria de referéndum, en la mayoría de los casos, asignado a la justicia constitucional. En Italia, la Ley constitucional n. ${ }^{\circ} 1$ de 11 de marzo de 1953 encarga a la Corte Constitucional el control sobre el respeto de los límites materiales impuestos en el artículo 75 de la Constitución. Las constituciones de los Länder alemanes atribuyen dicho control a su tribunal constitucional estatal. En Ecuador, la Corte Constitucional emite un dictamen previo y vinculante de constitucionalidad de la convocatoria de referéndum tanto a nivel nacional como autonómico (art. 443 Const.). En Uruguay, es la Suprema Corte de Justicia la encargada de 
En una democracia consolidada como la española debería ser posible el debate sobre la reforma constitucional del referéndum y la iniciativa popular sin que el eufemismo del «derecho a decidir» siga lastrándolo o sirviendo de coartada para no plantearlo. Ese debate es necesario, porque la ampliación de los canales de participación democrática no puede estar supeditada a la improbable superación de nuestra crisis territorial. Tras el franquismo, sin duda era necesario consolidar las instituciones representativas, fortalecer los partidos y lograr estabilidad política, pero, superada la etapa de consolidación de la democracia representativa, nada impide plantear una mayor participación de los ciudadanos en el proceso de formación de la voluntad general, de forma que, manteniendo la unidad de acción estatal, que es la función esencial de la representación política, no se menoscabe la fuerza legitimadora que la implicación popular proporciona al proceso político.

La iniciativa popular de referéndum o vinculada al referéndum viene avalada por su utilización en el Derecho comparado, donde opera como acicate de la representatividad y contrapeso del predominio parlamentario. La relevancia política de la iniciativa popular reside, no obstante, más «en sus posibilidades de interposición y en la permanente presencia y acción de todos los grupos políticos y sociales, que en el logro definitivo de los resultados normativos que en cada caso se plantean ${ }^{73}$. La iniciativa popular de referéndum protege al legislador, ante todo, de sí mismo, de su pasividad o resistencia a las demandas ciudadanas. Por eso, allí donde está instituida, la amenaza de su activación pesa. Y puede neutralizar las tentaciones de abuso en que la mayoría parlamentaria podría incurrir antes de llegar a hacerlo. Como evidencia su reconocimiento en el Derecho comparado, la posibilidad de activar la iniciativa popular para la celebración de referéndums estimula la receptividad de los representantes y la negociación entre los actores políticos. Una vez formalizada la iniciativa, las opciones de integración de las demandas ciudadanas continúan abiertas en sede parlamentaria, tanto si las iniciativas son propositivas, como si son abrogatorias. Y si, pese a las oportunidades abiertas a la negociación, finalmente el referéndum a instancia popular es convocado, los ciudadanos pueden pronunciarse sobre cuestiones que los representantes han omitido abordar y sobre la aceptación o rechazo que su actividad legislativa suscita, operando de este modo como garantía de cierre del sistema y mecanismo de equilibrio institucional.

Partiendo de estos presupuestos, la proposición de reforma constitucional de la Junta General del Principado de Asturias persigue la introducción en nuestro

velar por la constitucionalidad de las materias consultadas (art. 239.1 Const.). En Colombia corresponde a la Corte Constitucional decidir sobre la constitucionalidad de la convocatoria del referéndum de reforma constitucional (art. 241.1 Const.), un control que la importante Sentencia C-551/2003 de la Corte ha extendido a las materias excluidas de referéndum. En Hungría, es la Comisión Electoral Nacional la encargada de garantizar la constitucionalidad de las iniciativas de referéndum (art. 28/C5 Cont.). Y en Massachussets, esa función de control se atribuye al Fiscal General del Estado (Attorney General).

73 R. SÁNCHEz FÉRriz, «Formas y niveles territoriales de la iniciativa popular y del referéndum en el ordenamiento suizo", RDCE, n. ${ }^{\circ} 28,2017$, p. 3, disponible en https://www.ugr.es/ redce/REDCE28/articulos/01_FERRIZ.htm. 
ordenamiento jurídico de la iniciativa popular de referéndum en similares términos y con idénticas garantías a los reconocidos en otros países de nuestro entorno. La propuesta podrá o no compartirse, pero resulta totalmente injustificable que su toma en consideración por el Congreso de los Diputados siga demorándose sin que la Cámara haya aducido motivo alguno para ello. Debátase ya, racionalmente, sopesando los pros y los contras de esta forma de participación, oyendo a los promotores, contrastando la opinión de todos los grupos parlamentarios. Es lo menos que merece una iniciativa autonómica de este calado, la primera presentada al amparo del artículo 166.1 CE. Y es lo que merecen los ciudadanos. La democracia representativa en España no se resentirá por ello. Al contrario, saldrá fortalecida con ese debate.

\section{$* * *$}

\section{TITLE: Citizens' Initiative for Referendum}

ABSTRACT: Citizens' initiative for referendum is the power attributed to a number of citizens or to a percentage of them to trigger a referendum concerning a political question of general interest or a legislative text, thus giving the electorate the decision regarding its relevance, approval or repeal. Unlike initiatives for referendum attributed to sub-central entities in some composite states and initiatives granted to parliamentary minorities, citizens' initiative for referendum is generally acknowledged in comparative law. Where introduced, citizens' initiative for referendum is used to tackle the passivity or lack of receptiveness of legislators and to promote the adoption of constitutional or legislative reforms; it can also be used to control and correct the result of parliamentary processes involved in the formation of the general will. In this study, we will analyse the comparative regulation and practice of citizens' initiatives whose purpose is the holding of propositional referendums concerning rules and decisions of national importance, the ratification of voted but not enacted laws and the repeal of laws in force. We will also study the attempts to regulate citizens' initiatives in Spain, paying special attention to the proposal for constitutional reform approved by the General Board of the Principality of Asturias, which is still pending consideration.

RESUMEN: La iniciativa popular de referéndum es la facultad atribuida a un número de ciudadanos o a un porcentaje de ellos para instar la celebración de un referéndum sobre una cuestión política de interés general o sobre un texto normativo, remitiendo al cuerpo electoral la decisión sobre su oportunidad, su aprobación o su abrogación. A diferencia de la iniciativa de referéndum atribuida a los entes subcentrales en algunos Estados compuestos y de la iniciativa otorgada a las minorías parlamentarias, el reconocimiento de la iniciativa popular de referéndum está bastante extendido en el Derecho comparado. Donde está instituida, sirve para enfrentar la pasividad of falta de receptividad de los legisladores e impulsar la adopción de reformas constitucionales o legislativas. Y puede servir para controlar y corregir el resultado de los procesos parlamentarios de formación de la voluntad general. En este trabajo analizamos la regulación comparada de las iniciativas populares que tienen por objeto la convocatoria de referéndums propositivos sobre normas y decisiones de transcendencia nacional, de ratificación de leyes votadas y no sancionadas y de abrogación de leyes en vigor. También abordamos los intentos de regulación de la iniciativa popular de referéndum habidos en España, con especial atención a la proposición de reforma constitucional aprobada por la Junta General del Principado de Asturias, aún pendiente de toma en consideración.

KEY WORDS: citizens' initiative for referendum, direct democracy.

Palabras Clave: iniciativa popular de referéndum, democracia directa.

FECHA DE RECEPCIÓN: 30.09.2018

FECHA DE ACEPTACIÓN: 05.02.2019 
